\title{
Student Knowledge About the Water Cycle and Its Change in Different Interest Groups
}

\author{
Elina Malleus ${ }^{1} \&$ Eve Kikas ${ }^{1}$ \\ ${ }^{1}$ School of Natural Sciences and Health, Tallinn University, Tallinn, Estonia \\ Correspondence: Elina Malleus, School of Natural Sciences and Health, Tallinn University, Narva mnt 25, 10120 \\ Tallinn, Estonia. Tel: 372-55-655-630.
}

Received: March 25, 2019

Accepted: April 18, 2019

Online Published: April 20, 2019

doi:10.20849/jed.v3i1.564

URL: https://doi.org/10.20849/jed.v3i1.564

\begin{abstract}
This study describes the role of interest in eighth-grade students' $(\mathrm{N}=183)$ knowledge formation. Student knowledge was measured through open-ended questions at three time points: once before and twice after specific topics had been taught in a regular 45 min geography lesson. Student interest level was assessed using teacher ratings. Student answers to seven open-ended questions were coded and placed into one of three categories: everyday, synthetic, or scientific knowledge. Results showed that higher interest was related to providing fewer everyday and more synthetic answers. However, student answers changed similarly in all interest groups as measured before and after learning. The content of student answers tended to change as a result of the lesson, but these changes reflected the formation of new synthetic knowledge.
\end{abstract}

Keywords: knowledge development, knowledge about water cycle, interest, synthetic knowledge

\section{Introduction}

Studies have shown that understanding scientific explanations of natural phenomena is difficult, and even after several years of formal schooling, various scientifically inaccurate misconceptions persist (Duit \& Treagust, 2012; Frappart, \& Frède, 2006; Henriques, 2002; Vosniadou, Ioannides, Dimitrakopoulou, \& Papademetriou, 2001). Similar results have been reported about topics related to the water cycle (Ben-Zvi Assaraf \& Orion 2005; Cardak, 2009; Thompson \& Logue, 2006; Varelas, Pappas, \& Rife, 2006). To support student learning, it is important to examine different types of scientifically inaccurate knowledge (see Kikas, 2003; Vosniadou \& Brewer, 1992; 1994).

One way to describe scientifically inaccurate knowledge is to differentiate synthetic knowledge from everyday knowledge (Kikas, 1998b; 2003). Synthetic and everyday knowledge are not considered simply inaccurate (as has been suggested by earlier studies dealing with misconceptions); rather, synthetic and everyday knowledge can be conceptualized as different ways of making sense of abstract phenomena that cannot be physically experienced (for overview, see Kikas, 2003; Larraín, 2017; Toomela, 2003; Vosniadou, 1994, 2008; Vygotsky, 1986). Everyday knowledge stems from visible and/or perceptual information that is used to describe phenomena (e.g., "the water cycle is water that moves around"; "condensation is water droplets on the window"; Kikas, 2003; Toomela, 2003; Vygotsky, 1986). Synthetic knowledge (closely related to synthetic conceptions and fragmented conceptions) forms when everyday knowledge is combined with abstract scientific information (Kikas, 2003).

Synthetic knowledge may also have different subtypes that represent more or less coherent ways of combining information. These various subtypes of synthetic knowledge may have unique interactions with learned scientific knowledge when new information is provided (Diakidoy \& Kendeou, 2001). Identifying specific subtypes of synthetic knowledge related to the water cycle allows teachers to better understand the formation of inaccurate knowledge and to plan their syllabi accordingly.

Student motivation (i.e., interest, engagement) has also been highlighted as an important factor related to knowledge development. Thus, interest should be studied together with different types of knowledge (e.g., everyday, synthetic, and scientific; Sinatra \& Mason, 2013). Interest may support the development of scientific understanding, as students with higher interest levels tend to be more persistent and are more likely to use deep-level learning strategies (Andre \& Windschitl, 2003; Hadjiachilleos, Valanides, \& Angeli, 2013). Some 
studies also refer to the opposite possibility, that interest may support the persistence of existing scientifically inaccurate ideas (Sinatra \& Mason, 2013; Venville \& Treagust, 1998).

Our study aimed to describe eighth-grade students' everyday, synthetic, and scientific knowledge of the water cycle as it relates to interest. First, we described the prevalence of everyday, synthetic, and scientific knowledge in groups of students with different teacher-rated interest levels. While student self-evaluations are usually used in assessing interest, it is also important to understand how teachers perceive student interest and how these ratings are related to changes in student knowledge. Second, we studied changes in knowledge in groups with different interest levels before and after an ordinary curriculum-based lesson. Third, we analyzed specifically students' synthetic answers when describing the overall process of the water cycle and described changes between different subtypes. While the Estonian National Curriculum (Vabariigi Valitsus, 2011/2018) emphasizes constructivist methods, such methods may not be easy to implement for all teachers. Thus, it is also important to describe if and how knowledge about important topics (e.g., the water cycle) changes in an ordinary learning environment. Student knowledge was measured at three time points: just before the classroom lesson, right after the lesson, and four months later.

\subsection{Learning and the Development of Everyday and Synthetic Knowledge}

Learning about the water cycle is difficult as it involves processes like evaporation and cloud formation which cannot be directly observed. Even though other water cycle processes are visible (e.g. rainfall), students must still create abstract relations between different concepts to accurately describe a given phenomenon. As a result, children may form everyday knowledge that refers to perceptions of the visible world based on everyday observations and experiences (Hannust \& Kikas, 2007; Malleus, Kikas \& Marken, 2017; Kikas, 2003; Wiser \& Amin, 2001). For example, students may compare cloud formation to steam in the bathroom after showering (Thompson \& Logue, 2006), or may describe evaporation as steam escaping when a pot is boiling (Varelas, Pappas, $\&$ Rife, 2006).

When exposed to accurate scientific information, children often consolidate prior experiences with such scientific information to form synthetic models (Vosniadou, 2012) or synthetic knowledge (Kikas, 1998b, 2003). Synthetic knowledge has been described by some authors as highly internally consistent and highly accommodating of new knowledge (Vosniadou \& Skopeliti, 2014, 2017). Others have described synthetic knowledge as less integrated, composed primarily of fragmented concepts and knowledge (DiSessa, 2002; Panagiotaki, Nobes, \& Banerjee, 2006; Özdemir \& Clark, 2007). In our study, we combined different approaches and defined synthetic knowledge broadly. We consider synthetic knowledge as stemming from explanations which combine everyday perceptual knowledge and abstract scientific information (Kikas, 2003). Therefore, synthetic knowledge may develop as a result of 1) simplifying and/or assimilating scientific information to fit with everyday experiences, or 2) using fragments of scientific information without proper integration.

Prior studies have shown that, students may form synthetic knowledge about condensation and evaporation by imagining water moving in the atmosphere or under the ground (Covitt, Gunckel, \& Anderson, 2009). Moreover, students hold a variety of inaccurate conceptions related to the water cycle. Some students show difficulty in understanding the overall process of the water cycle (Ben-zvi-Assarf \& Orion, 2005), while others show incomplete knowledge of the process or fail to correctly integrate different pieces of scientifically accurate information. For example, when describing cloud formation, some students only describe the upper part of the water cycle or mix the processes of condensation and evaporation (Cardac, 2009; Sibley, Anderson, Heidemann, Merrill, Parker, \& Szymanski, 2007; Thompson \& Logue, 2006). Thus, students may develop different subtypes of synthetic knowledge that warrant additional study.

Synthetic knowledge may be a good transitional step toward scientific understanding; however, it is unlikely that students will acquire scientific knowledge without exposure to specific conceptual-change oriented teaching methods (Carey \& Smith, 1993; Tytler, 2002). Moreover, without such exposure, students may be prone to the development of additional synthetic knowledge (Diakidoy, Vosniadou, \& Hawks, 1997; Hannust \& Kikas, 2007). Describing synthetic knowledge related to cloud formation and rainfall study has also shown that different types of synthetic knowledge is evident already in kindergarteners and elementary school students' answers (Malleus, Kikas \& Marken, 2017). Changes may be gradual and occur between different subtypes of synthetic knowledge (Diakidoy \& Kendeou, 2001), and some subtypes of synthetic knowledge may be more persistent than others (González, 1997).

Students may also acquire verbalisms - scientific-like descriptions in which learned material is regurgitated using exact words, but without true comprehension. Similarly, researchers have described the short-term effects of repetition-based practice. These short-term improvements do not support long-term learning, where a slower 
overall process and navigating through mistakes has been shown to be more effective (Soderstrom \& Bjork, 2015). In time, verbalisms may also convert into different types of synthetic knowledge (see Kikas, 1998a). Synthetic descriptions often offer satisfactory explanations about the world, thus students may remain content with their synthetic understanding and not seek out additional information ((Brewer, Chinn, \& Samarapungavan, 2000; Eberbach \& Crowley, 2009; Kikas, 2003).

\subsection{The Role of Interest in the Process of Knowledge Construction}

In addition to existing knowledge, different motivational factors play an important role in the development of proper scientific understanding (Krapp, 1999; Linnenbrink \& Pintrich, 2003; Pintrich et.al., 1993, Sinatra, 2005). We examined teacher-rated interest in students as one possible factor that may support the construction of scientific knowledge.

Interest is defined as the psychological state of liking, valuing, and enjoying the process of engaging in a particular activity or topic (Linnenbrink \& Pintrich, 2002; Schiefele, 2009). Experimental research has shown that interest is more strongly related to deep-level than surface-level information processing; in other words, interested students strive for a better understanding and are more persistent toward that goal (Andre \& Windschitl, 2003; Hadjiachilleos et al., 2013). Deep-level learning strategies, in turn, tend to support better scientific understanding (Schiefele, 1999; Wigfield \& Cambria, 2010). In their overview of studies, Sinatra and Mason (2013) concluded that higher interest levels may support conceptual-change processes or may inversely contribute to a higher commitment to one's existing ideas. Thus, different instructional approaches may be needed.

Classically, student interest — including attention, effort, activity, and enthusiasm - has been measured through self-evaluations in which students were asked to rate their level of enjoyment and persistence on certain assignments (e.g. Ainley, Hidi, \& Berndorff, 2002; Kang, Scharmann, Kang, \& Noh, 2010). Teacher ratings represent another, less common method of assessing student interest. Studies have shown that, when considering learning effort and enjoyment, student reports and teacher ratings are positively correlated (Zhu \& Urhahne, 2014). When promoting self-awareness and supporting the construction of scientific understanding, teachers consider student interest as exhibited in their learning behavior (Zhu \& Urhahne, 2014). Thus, teachers may pay more attention to behavioral aspects reflecting students' interest than the students themselves who may consider interest more as simply liking specific topics.

Teacher ratings may therefore represent a good way of describing student interest that is related to their actual learning behavior and should be described together with changes in knowledge. Thus, we used teacher ratings of student interest to explore changes in everyday, synthetic, and scientific knowledge of the water cycle.

\subsection{Learning About the Water Cycle in Estonian Schools}

The topic of the water cycle was selected because its sub-processes (cloud formation, rainfall) are easily observable by children from an early age. However, proper scientific explanation of the water cycle requires a complete understanding of different cyclical processes and abstract subtopics - such as evaporation and condensation - that are difficult for students to understand. Therefore, a synthesis of everyday experience and scientific knowledge is likely to emerge (Covitt, Gunckel, \& Anderson, 2009).

Although constructivist practices are recommended by the Estonian National Curriculum (Vabariigi Valitsus, 2011/2018), and although teachers report that they value constructivist practices, traditional methods are used more often in regular Estonian classroom settings (Teaching and Learning International Survey, 2009, 2013). It has been shown that traditional methods in Estonian schools vary significantly between subject areas, with science teachers tending to use more traditional methods than social studies teachers (Teaching and Learning International Survey, 2013). Implementing constructivist teaching practices — and, more specifically, conceptual-change oriented teaching practices - is a process that takes time. Thus, it is important to study changes in knowledge in ordinary teaching environments rather than in controlled, conceptual-change oriented classroom lessons.

In Estonia, topics related to the water cycle are taught gradually and cumulatively (spiral curriculum; see Bruner, 1960/1999). In Grade 2, students focus on observing weather (cloud formation and rain). From Grades 4-6, different weather phenomena are discussed in relation to the water cycle. After graduating from Grade 6, Estonian students are expected to be able to explain different parts of the water cycle and the role of temperature in this process (Vabariigi Valitsus, 2011/2018). In Grade 7, different states of water are discussed with more specificity, and in Grade 8, general topics of the water cycle are revised in the context of weather processes and bodies of water. By the time Estonian students reach the eighth grade, topics related to the water cycle are distilled into one 45-minute lesson. More specifically, the water cycle is the first subtopic of a larger "Water Resources" unit that lasts approximately three months (15 lessons). 


\subsection{Objectives and Hypothesis}

Prior studies have shown that synthetic knowledge about the water cycle is common in students of various ages ( Ben-Zvi Assaraf \& Orion 2005; Cardak, 2009; Malleus, Kikas \& Marken, 2017; Thompson \& Logue, 2006; Varelas, Pappas, \& Rife, 2006). Our study sought to describe the effects of interest (as rated by teachers) on eighth-grade students' knowledge and how student knowledge changes during and after an ordinary classroom lesson. Student knowledge was assessed before the lesson, right after the lesson, and four months later (T1, T2, and T3, respectively). Interest was assessed via teacher ratings before the lesson. Based on these ratings, three interest groups were created: high, average, and low.

More specifically, our study aimed (1) to compare the frequency of students' everyday, synthetic, and scientific answers in different interest groups, (2) to describe changes in students' everyday, synthetic, and scientific answers among different interest groups right after and four months after a classroom lesson, and (3) to compare different subtypes of synthetic answers that students use to describe the process of the water cycle in different interest groups before and after the lesson. The specific research questions and hypotheses were as follows.

First, do students in high, average, and low interest groups differ in their everyday, synthetic, and scientific answers? An earlier study showed that, in general, younger students tend to give more synthetic answers than scientific or everyday answers (Malleus, Kikas \& Marken, 2017). However, synthetic answers have not been found to be directly related to self-rated student interest. As teacher ratings of student interest have been shown to be related to aspects of student engagement that support deep learning (Andre \& Windschitl, 2003; Hadjiachilleos, Lee \& Reeve, 2012; Urhahne, 2011; Valanides, \& Angeli, 2013), we expected that students in the high interest group would give fewer synthetic and everyday answers, and more scientific answers, as compared with students in average and low interest groups.

Second, how does everyday, synthetic, and scientific knowledge about the water cycle change in groups of students with high, average, and low interest during and after the lesson? We hypothesized that changes in knowledge right after the lesson would be similar to those four months after. As student engagement and interest are related to changes in scientific knowledge formation (Andre \& Windschitl, 2003; Hadjiachilleos, Valanides, \& Angeli, 2013), we hypothesized that students in the high interest group would give fewer everyday answers and more scientific answers after learning as compared to their answers before learning. We further hypothesized that students in the high interest group would give fewer everyday answers and more scientific answers after learning as compared to students in the low interest group. However, it has been shown to be difficult and time consuming for students to change their answers from synthetic to scientific (Carey \& Smith, 1993; Tytler, 2002). Furthermore, exposure to scientific knowledge may evoke new synthetic concepts (Diakidoy, Vosniadou, \& Hawks, 1997; Hannust \& Kikas, 2007). Thus, we also expected that students in the high interest group would give more synthetic answers after learning as compared to before learning. We also hypothesized that students in the high interest group would give more synthetic answers after learning as compared to students in the low interest group.

Third, what kind of answers do students give to the question, "What is the water cycle?" at different time points, and is there any difference between interest groups? Moreover, how do student answers change, and how do these changes differ among interest groups? We assumed that this question would be the most difficult to answer because scientific answers presume integration of information from different sources and a complete understanding of the entire process as a cycle. Studies have shown that students of different ages struggle with understanding this process (Ben-zvi-Assarf \& Orion, 2005; Cardak, 2009; Sibley, et.al., 2007; Thompson \& Logue, 2006).

In addition to everyday and scientific answers, we searched for subtypes of synthetic answers that were either more or less similar to everyday or scientific answers. We expected that students in the high interest group would give more synthetic answers that are more similar to scientific answers and fewer everyday answers. We also expected to find changes among subtypes of synthetic answers before and after learning. We assumed that there would be more students whose answers would change towards being more similar to scientific answers after being taught, as compared to students whose answers did not change. With respect to interest, we hypothesized that students in the high interest group would have more changes in their answers and would give more answers that are similar to scientific answers after being taught, as compared to students in the average or low interest groups.

\section{Method}

\subsection{Participants}

Overall, 238 eighth-grade students (98 boys, mean age $=14$ years) participated in the study. As a result of unforeseeable student absences, the number of participants varied between time points, and some analyses were 
performed with fewer students. 183 students participated in all data-collection time points and were included in subsequent analyses. Student participants came from 10 classes in five schools from different parts of Estonia. Five geography teachers (all female) participated in the study. Two of the teachers had work experience of less than five years; one 5-15 years of work experience; and two had more than 15 years of work experience.

\subsection{Instruments}

\subsubsection{Knowledge Test}

Students were asked the same seven open-ended questions at three different time points. All questions were related to the water cycle. First, students were asked to define concepts such as the water cycle, evaporation, condensation, clouds, and rain. Second, students were asked to answer the following two questions: "How do clouds form?" and "Why do some clouds produce rain while others do not?" Similar questions have been used in previous studies (cf. Malleus, Kikas \& Marken, 2017; Taiwo, Ray, Motswiri \& Masene, 1999; Thompson \& Logue, 2006).

During analysis, student answers were first coded into narrow types by reflecting different subtypes of everyday, synthetic and scientific answer categories. The coding system was based on theoretical bases and previous studies (cf. Malleus, Kikas \& Marken, 2017 for specific descriptions and Kikas, 2003; Toomela, 2003; Vosniadou, 1994; 2008; Vygotsky, 1986 for theoretical bases). Narrower synthetic answer types reflecting answers to the question "What is the water cycle?" were used in one analysis related to research question number three. A specific description of these subtypes is presented in Table 1 .

Table 1. Percentage of students giving different types of answers for defining water cycle

\begin{tabular}{|c|c|c|c|}
\hline Category of an answer & $\begin{array}{r}\text { Before } \\
\text { learning } \\
(\%)\end{array}$ & $\begin{array}{l}\text { Right after } \\
\text { learning } \\
(\%)\end{array}$ & $\begin{array}{l}\text { Four } \\
\text { months } \\
\text { after } \\
\text { learning } \\
(\%)\end{array}$ \\
\hline Don't know & 20.2 & 12.4 & 8.4 \\
\hline $\begin{array}{l}\text { Everyday: descriptive answers of water moving around (personified } \\
\text { constructions, describing more object than process) and defining } \\
\text { through the concept itself. }\end{array}$ & 21.9 & 24.7 & 17.4 \\
\hline $\begin{array}{l}\text { Synthetic Subtype 1: Describing movements of water while not } \\
\text { describing different states of water (inside lake, river or between } \\
\text { different lakes/rivers/oceans) }\end{array}$ & 15.2 & 9.0 & 5.1 \\
\hline $\begin{array}{l}\text { Synthetic Subtype 2: Including daily knowledge in descriptions } \\
\text { incorrectly. Slightly describes changes of states using elements } \\
\text { from everyday understanding when describing visible features: e.g. } \\
\text { when water moves though different states (personified), when } \\
\text { boiling water eventually turns into clouds and rains down, when } \\
\text { water evaporates and then stops, when water changes states while } \\
\text { boiling and freezing }\end{array}$ & 16.9 & 13.5 & 21.9 \\
\hline $\begin{array}{l}\text { Synthetic Subtype 3: Using learnt terms in fragmented manner } \\
\text { (describes moving using scientific type new information in } \\
\text { fragmented way referring to atmosphere, temperature, exchange of } \\
\text { water in the world, big and little water cycle) }\end{array}$ & 10.7 & 26.4 & 30.3 \\
\hline $\begin{array}{l}\text { Synthetic Subtype 4: Partial description of the process (tries to } \\
\text { describe the cyclic nature/process of water cycle: e.g. process } \\
\text { where water changes states and there is no end, process where } \\
\text { water moves between atmosphere and the ground or names } \\
\text { different parts of the processes, but not all) }\end{array}$ & 13.5 & 12.9 & 15.7 \\
\hline $\begin{array}{l}\text { Scientific: describing the cyclic nature or water cycle and also all } \\
\text { the sub-processes of the phenomena. }\end{array}$ & 1.7 & 1.1 & 1.1 \\
\hline
\end{tabular}

Second, the coded answers were integrated into four broader categories: missing/don't know, everyday, synthetic, or scientific. Each student received four sum scores. For example, if a student had given two scientific answers and 
five synthetic answers, the student's scores would be 0 for the 'missing' and 'everyday' category; 5 for the 'synthetic' category; and 2 for the 'scientific' category. The maximum possible score for each category was 7. Sum scores for the 'missing/don't know' category were excluded from further analysis as this was not the focus of the present study. The three other sum scores were used in subsequent analyses.

Answers were coded by different researchers using specific schema established in previous studies (Ben-zvi-Assarf \& Orion, 2005; Cardak, 2009; Malleus, Kikas \& Marken, 2017; Sibley, et.al., 2007; Thompson \& Logue, 2006). To facilitate coding, examples from previous studies were created for each subtype. For instance, everyday answers described clouds as containers which collect moisture, or described evaporation as water disappearing into the sky. Synthetic answer codes were given when students' for example 1) confused the processes of evaporation and condensation, 2) incorrectly discussed other concepts in the wrong context (e.g., solidity, air pressure), or 3 ) gave incomplete information. To be marked as scientific, an answer had to describe the overall concept using scientifically correct information (e.g., condensation is a process where substance in a gaseous state transforms into a liquid state).

The coding process was as follows. First, $50 \%$ of the answers were coded by one researcher based on the schema. Next, another researcher individually reviewed the same $50 \%$ of answers. When comparing the results, it was found that the researchers disagreed about the coding category for $32 \%$ of answers. These answers were further discussed until 100\% agreement was attained. The coding schema was then reviewed and improved before coding the second half of the answers. Again, one researcher coded the other $50 \%$ of the answers individually, followed by the second researcher coding the same $50 \%$ of answers. For these answers, the researchers disagreed about the coding category for $15 \%$ of answers. These answers were discussed until the researchers reached full consensus on the coding of all answers.

\subsubsection{Interest}

To classify interest level, geography teachers were first given a list of all students in the class. Next, they were asked to categorize students who were either a) more interested in weather-related topics, or b) less interested in weather-related topics. Students without strong interest in weather-related topics were left unmarked. Teachers marked 58 students as less interested (25.9\%), 66 students as more interested $(31.1 \%)$, and did not mark 88 students (41.5\%). These three interest groups - low, average (not marked), and high — were used in subsequent analyses.

\subsection{Procedure}

This study was part of a larger three-year research project entitled "General competencies and their assessment." This project aimed to evaluate the development of general competencies in middle school students. The data collection process was approved by an ethical committee. First, eight school principals were contacted and asked for permission to carry out the study. Next, geography teachers were asked to participate. Teachers who consented were asked to describe their personal syllabus to establish when relevant topics were covered in their classroom lessons. The study only included classes which covered the water cycle in the fall term ( 5 schools, 10 classes). Finally, all participating parents were asked for informed consent. Only students with parental permission were included in the study.

The first author of the paper conducted written tests assessing general knowledge at three time points: T1 — before the lesson; T2 - the next geography lesson after relevant topics were covered; and T3 - four months after the "Water Resources" unit ended. Students completed the test within approximately 25 minutes.

First, before the lesson, all students completed the general knowledge test. While students completed the test, teachers were asked to categorize students based on interest level. Next, all students in the sample participated in an ordinary geography lesson (45 minutes in duration) that covered topics related to the water cycle. In the next lesson, the second test of student knowledge was administered. All students continued to participate in subsequent lessons covering topics related to water resources (one lesson per week for 11 consecutive weeks). After this unit concluded, students were tested a third and final time.

Topics covered included the following: distribution of water resources on earth, world seas, water temperatures, ice conditions on the sea, the effects of flowing water, flooding, water reservoirs, and the use and protection of water bodies. Teachers were not asked to use specific conceptual-change oriented teaching methods. Rather, lessons reflected teachers' ordinary teaching practices and were based on the standard national curriculum. All lessons covering the water cycle were recorded and later transcribed. Subsequent analysis from recorded lessons and teachers' own evaluations revealed that, although teachers used different methods (including learner-centered methods), teacher-directed methods were used the majority of the time. 


\subsection{Data Analysis}

Sum scores for everyday $(\operatorname{Min}=0$; $\operatorname{Max}=5)$, synthetic $(\operatorname{Min}=0 ; \operatorname{Max}=7)$, and scientific answers $(\operatorname{Min}=0$; $\operatorname{Max}$ $=6$ ) were calculated for seven questions. These sum scores were used as dependent variables in a subsequent Repeated Measures Analysis of Variance (ANOVA). Post-hoc tests were carried out using Bonferroni correction. Partial $\eta^{2}$ was used as a measure of effect size (further named $\eta^{2}$ ).

Different answers to the question "What is the water cycle?" were analyzed with crosstabs using frequency statistics. Different subtypes of synthetic answers were listed and presented on a hypothetical scale based on their similarity with everyday category or scientific category (further named as lower order synthetic answers and higher order synthetic answers). Different combinations of answer types across different time points and in relation to different interest groups were analyzed using Configural Frequency Analysis from the Sleipner statistical package (Bergman \& El-Khouri, 2002; von Eye, Spiel, \& Wood, 1996). Configural Frequency Analysis (CFA) compares expected and observed frequencies of combinations of variables and evaluates whether this difference is bigger than chance (von Eye, 2003). Combinations may occur more often than expected (referred to as types) or less often than expected (antitypes). Configural Frequency Analysis was chosen as it allows researchers to describe individual changes in student answer patterns and is widely used in person-oriented research (e.g. Bergman \& El-Khouri, 2002). Example CFA data is shown in Appendix A.

\section{Results}

\subsection{Everyday, Synthetic, and Scientific Answers in Three Interest Groups Before and After the Lesson}

Table 2 presents descriptive statistics for everyday, synthetic, and scientific answers in different interest groups before, right after, and four months after the lesson.

Table 2. Descriptive statistics in T1, T2, T3 for everyday, synthetic and scientific answers in whole sample and different interest related groups

\begin{tabular}{|c|c|c|c|}
\hline & \multicolumn{3}{|c|}{ Interest groups } \\
\hline & Low & Average & High \\
\hline & $\mathrm{M}(\mathrm{SD})$ & $\mathrm{M}(\mathrm{SD})$ & $\mathrm{M}(\mathrm{SD})$ \\
\hline \multicolumn{4}{|l|}{$T 1$} \\
\hline Everyday & $0.93(1.05)$ & $0.78(0.92)$ & $0.61(0.65)$ \\
\hline Synthetic & $2.96(1.65)$ & $3.86(1.70)$ & $4.34(1.48)$ \\
\hline Scientific & $0.08(0.08)$ & $0.92(0.88)$ & $1.11(0.97)$ \\
\hline \multicolumn{4}{|l|}{$T 2$} \\
\hline Everyday & $1.24(1.15)$ & $0.70(0.81)$ & $0.45(0.63)$ \\
\hline Synthetic & $3.00(1.66)$ & $3.56(1.57)$ & $4.21(1.25)$ \\
\hline Scientific & $1.20(1.10)$ & $1.51(1.18)$ & $1.63(1.12)$ \\
\hline \multicolumn{4}{|l|}{$T 3$} \\
\hline Everyday & $0.87(0.87)$ & $0.74(0.93)$ & $0.41(0.65)$ \\
\hline Synthetic & $3.73(1.59)$ & $3.84(1.49)$ & $4.61(1.17)$ \\
\hline Scientific & $1.11(1.05)$ & $1.29(1.22)$ & $1.57(1.08)$ \\
\hline
\end{tabular}

Three separate 3 (interest: low, average, high) x 3 (time: T1, T2, T3) Repeated Measures ANOVAs were conducted for everyday, synthetic, and scientific answers. A significant main effect of interest was shown for everyday $\left[\mathrm{F}(2,171)=10.00, p=.001, \eta^{2}=.10\right]$ and synthetic $\left[\mathrm{F}(2,174)=13.50, p=.001\right.$, partial $\left.\eta^{2}=.13\right]$ answers. Students in the high interest group had overall lower scores of everyday answers $(\mathrm{M}=0.48, \mathrm{SD}=0.07)$ compared to other groups (low $\mathrm{M}=1.01, \mathrm{SD}=0.08, p=.04$; average $\mathrm{M}=0.73, \mathrm{SD}=0.06, p=.001$ ). Students in the high interest group also had higher scores of synthetic answers $(\mathrm{M}=4.38, \mathrm{SD}=0.15)$ compared to other groups (average $\mathrm{M}=3.71, \mathrm{SD}=0.13, p=.001 ;$ low $\mathrm{M}=3.23, \mathrm{SD}=0.17, p=.01$ ). A significant main effect of assessment time was found for synthetic $\left[\mathrm{F}(2,348)=5.37, p=.01\right.$, partial $\left.\eta^{2}=.03\right]$ and scientific $[\mathrm{F}(2,348)=15.74, p=.001$, partial $\left.\eta^{2}=.08\right]$ answers. Students gave more synthetic answers at $\mathrm{T} 3(\mathrm{M}=4.03, \mathrm{SD}=0.11)$ than $\mathrm{T} 1(\mathrm{M}=3.71, \mathrm{SD}$ $=0.12, p=.001)$ or $\mathrm{T} 2(\mathrm{M}=3.58, \mathrm{SD}=0.12, p=.01)$. More scientific answers were given at $\mathrm{T} 2(\mathrm{M}=1.43, \mathrm{SD}=$ $0.09, p=.001)$ and $\mathrm{T} 3(\mathrm{M}=1.31, \mathrm{SD}=0.09, p=.001)$ than at $\mathrm{T} 1(\mathrm{M}=0.94, \mathrm{SD}=.07)$. No significant interactions were found between interest groups and assessment times. 


\subsection{Analyzing the Answers to the Question "What Is the Water Cycle?"}

As compared with other questions, and as predicted, students gave the lowest number of scientific answers to the question "What is the water cycle?". Specifically, $2 \%$ of students gave scientific answers to this question before learning, and just $1 \%$ of students gave scientific answers to this question after learning. On the other hand, $8-46 \%$ of answers given to other questions were scientific. Data reflecting the frequency of different types and subtypes of answers given to the question "What is the water cycle?" at three time points is presented in Table 1.

Multiple Configural Frequency Analyses (CFA) were carried out to examine patterns among answer types, interest groups, and time points. An example of one analysis is presented in Appendix A. At T1, students in the high interest group gave more synthetic answers than expected $(p=.02$; observed frequency $=14$; expected frequency $=7.53$ ). At T2, students in the low interest group gave more everyday answers than expected $(p=.001$; observed frequency $=22$; expected frequency $=10.81$ ). In contrast, students in the high interest group gave fewer everyday answers than expected $(p=.03$; observed frequency $=7$; expected frequency $=13.83)$. At T3, students in the high interest group gave fewer 'don't know' answers than expected $(p=.01$; observed frequency $=0$; expected frequency $=$ $4.23)$, and fewer everyday answers than expected $(p=.03$; observed frequency $=4$; expected frequency $=9.77)$, but more synthetic answers than expected $(p=.01$; observed frequency $=29$; expected frequency $=17.58)$. Students in the low interest group gave more everyday answers than expected $(p=.03$; observed frequency $=13$; expected frequency $=7.50)$ and fewer synthetic answers than expected $(p=.02 ;$ observed frequency $=6$; expected frequency $=13.50$ ).

$69 \%$ of student answers changed categories between T1 and T2. More specifically, in T2, 26\% of students gave higher-order synthetic answers (moved towards more scientific understanding) and $20 \%$ of students gave lower-order synthetic answers. $73 \%$ of student answers changed categories between T1 and T3. More specifically, in T3, 35\% of students gave higher-order synthetic answers and 19\% of student gave lower-order synthetic answers.

Two Configural Frequency Analyses compared different interest groups before and after the lesson. Between T1 and T2, three combinations appeared as significant types. Students in the low interest group gave more everyday answers than expected, both before and after the lesson $(p=.01$; observed frequency $=8$; expected frequency $=$ 2.41). Students in the high interest group gave more synthetic answers than expected in synthetic answer subtype 1 $(p=.01 ;$ observed frequency $=4$; expected frequency $=1.78)$ and $3(p=.01$; observed frequency $=6$; expected frequency $=1.67$ ), both before and after the lesson.

At both $\mathrm{T} 1$ and $\mathrm{T} 3$, more students than expected in the high interest group gave synthetic answers listed as Subtype $1(p=.01$; observed frequency $=3$; expected frequency $=0.47)$ and $3(p=.01$; observed frequency $=7$; expected frequency $=1.96$ ). In addition, across both $\mathrm{T} 1$ and $\mathrm{T} 3$, more students than expected in the high interest group gave synthetic answers in Subtype $4(p=.05$; observed frequency $=4$; expected frequency $=1.23)$. At T1, students in the high interest group gave more synthetic answers in Subtype 2, while at T3, students in the high interest group gave more synthetic answers in Subtype 3 ( $p=.05$; observed frequency $=7$; expected frequency $=2.90)$. At T1, students in the average interest group gave more synthetic answers in Subtype 2 than expected, while at T3, students in the average interest group gave more scientific answers than expected $(p=.01$; observed frequency $=2$; expected frequency $=0.14$ ).

\section{Discussion}

Our study aimed to examine eight-grade students' everyday, synthetic, and scientific knowledge about the water cycle before and after a regular classroom lesson. We found that student answers varied depending on their level of interest, such that students in the high interest group gave more synthetic answers and fewer everyday answers compared to students in other interest groups. Changes in answers before and after the lesson were similar in all interest groups, but students gave more scientific answers after the lesson as compared to before the lesson. In all interest groups, students were found to give more synthetic answers four months after learning as compared to right after the lesson. The most difficult question for students was "What is the water cycle?". At all time points, students proposed different synthetic answers to this question.

\subsection{Everyday, Synthetic, and Scientific Knowledge Before and After the Lesson in Three Interest Groups}

We expected student answers to change depending on their interest group, but our hypothesis was only partially confirmed. Students rated as highly interested gave fewer everyday answers and more synthetic answers at all time points when compared to students in the average and low interest groups.

Previous studies have reported an effect of higher interest on deeper-level learning, since interested students use more-efficient learning strategies that help them successfully restructure their knowledge (Andre \& Windschitl, 
2003; Hadjiachilleos, Valanides, \& Angeli, 2013; Schiefele, 1999; Wigfield \& Cambria, 2010). Therefore, interested students may give fewer everyday answers. However, this does not imply that these students have acquired true scientific understanding. Studies in conceptual change have shown that interest can also support maintaining existing understandings (for an overview, see Sinatra and Mason, 2013). Synthetic answers, in particular, have been shown to be quite resistant to change (Boylan, 2009; Carey \& Smith, 1993; Tytler, 2002). While everyday answers may seem less plausible (and are therefore more susceptible to change), synthetic explanations may be perceived as sufficient to describe the phenomena (and are thus less likely to change).

Unexpectedly, student answers changed similarly across the three interest groups. Students in all interest groups gave more scientific answers immediately after the lesson, and more synthetic answers four months after the lesson. Therefore, the lesson seemed to act as a beneficial revision of water cycle topics, but only in the short term (Soderstrom \& Bjork, 2015). However, the prevalence of synthetic answers, even directly after the lesson, suggests a need for more research to fully understand long-term learning and associated comprehension. As students were taught about water resources over a four-month period, it is possible that student knowledge related to the water cycle may have changed; furthermore, new synthetic knowledge may have been formed.

Our choice to use teacher ratings as a measure of student interest may have affected the results. Prior studies have shown that teacher ratings are similar to student reports, but for teachers, student interest may be more visible through aspects related to engagement, and these aspects have been shown to have a direct impact on knowledge acquisition (Ainley, Hidi, \& Berndorff, 2002; Kang, Scharmann, Kang, \& Noh, 2010; Krapp, 1999). Therefore, teacher ratings of students' interest may be important to describe in relation to the development of true scientific understanding, but this aspect alone may not be enough. Teachers ratings should be studied together with students' estimates and other factors should be included. For instance, expectancy-value theory posits that other variables like learners' self-efficacy beliefs — play similarly important roles in learning engagement (Eccles, 2005; Linnenbrink-Garcia et. al., 2012). This suggests that even students with higher interest (and engagement) may need more time and support from their teachers in order to develop true scientific understanding, but these motivational aspects can be explicitly taken into account by teachers to support students' learning.

\subsection{Defining the Water Cycle}

The water cycle is a complex phenomenon - a cyclical process consisting of several sub-processes that are not directly perceptible, and thus difficult to understand in a short period of time. To investigate synthetic answers in more detail, we analyzed answers to the question "What is the water cycle?" separately. As expected, and similar to previous studies (Ben-Zvi Assaraf \& Orion 2005; Cardak, 2009; Sibley, et al., 2007; Thompson \& Logue, 2006), only a minority of students gave scientific answers to the question "What is the water cycle", while the majority of answers were synthetic. This suggests a need to study the emergence of synthetic concepts in order to combat misinformation and support better, more-accurate understanding in students.

We divided overall synthetic answers into separate subtypes, some of which were more similar to everyday answers and others more similar to scientific answers (see Table 1). With the exception of Subtype 1, similar subtypes have been described in previous studies (Ben-zvi-Assarf \& Orion, 2005; Cardak, 2009; Sibley et.al., 2007; Thompson \& Logue, 2006). Synthetic answers listed in Subtype 1 described the water cycle as liquid moving between different bodies of water or inside a lake. Answers in Subtype 1 were most similar to everyday answers, but still reflected parts of learned scientific material. These answers may have been impacted by the specifics of the Estonian language. In Estonian, veeringe (the water cycle) is a compound word comprised of two common words (vee - water, and ringe - circle or cycle). Many other natural processes can be described using similar words, and these overlapping definitions may have confused some students. This description was less often used by students after the lesson in comparison with the descriptions before the lesson. Thus, some students may recognize the need to specify their answer in this context even after short lesson.

Synthetic answers in Subtype 2 described changes in water states using elements from everyday understanding, such as vapor that is visible during boiling. These answers used the words boiling and freezing, but also reflected students' difficulties with defining the water cycle as a system. Answers in Subtype 2 tended to use wording that was more appropriate for describing objects than a system.

In Subtype 3, students used fragments of different concepts related to the water cycle. These answers created new associations, but failed to describe the real process of the water cycle. For example, student answers often used terms like atmosphere or temperature, but did not explain the connection between these terms and the water cycle. Students also confused the processes of condensation and evaporation. Answers that were listed under Subtype 3 were most frequently used by students after the lesson. This is consistent with prior studies, which have described difficulties in student comprehension regarding environmental elements (Vosniadou, 2013; Vosniadou \& 
Skopeliti 2017). Answers in Subtype 3 reflected student attempts to integrate different pieces of scientific information without having a complete understanding of the process as a whole. Answers in Subtype 4 were the closest to scientific answers. These answers left out only one sub-process of water-cycle from their description, but described the cyclical nature. Other answers in Subtype 4 only identified all sub-processes correctly while failing to describe the cyclical nature of the water cycle. Answers in Subtype 4 did not reflect overall misunderstanding of the process, but rather lacked specific details that are necessary to a full understanding of the water cycle.

When describing the difference between given answers according to different interest groups we found that students in the high interest group tended to give more than expected synthetic answers in Subtype 4, even before the lesson. This may be because interested students may pay more attention to relevant topics in earlier lessons, resulting in later recall of isolated facts without a full scientific understanding of the process. Thus teaching of these students should be focused on supporting the development of systemic understanding. Four months after the lesson, more students than expected in the high interest group gave synthetic answers in Subtype 3. Other studies have also shown that, after teaching, the content of synthetic answers is prone to change (e.g., Hannust \& Kikas, 2007). Namely, synthetic answers in Subtype 3 attempted to explain the water cycle in relation to other abstract concepts that students had only recently learned (e.g., temperature, the atmosphere). Interested students may pay attention to topics related to the water cycle in other classes, thereby reorganizing their understanding with new concepts and ideas. This may result in fragmented descriptions, as new information might not be fully understood or properly integrated with existing knowledge. The fact that more students in the high interest group gave synthetic answers in Subtype 4 before the lesson, and in Subtype 3 four months after the lesson, may also refer to the possibility that Subtype 4 answers include verbalisms in which scientific words are simply memorized, but not truly understood (Kikas, 1998a). Further studies are needed to more accurately understand the development of synthetic knowledge over time as described patterns only reflected small difference between some students.

As expected, changes in synthetic answers over time were generally toward subtypes that were more similar to scientific answers (higher-order answers). Even in traditional settings, student answers tend to change after a short lesson, but instead of forming scientific knowledge, various types of synthetic knowledge is formed. Some students' answers did not change. For example it was found that even highly interested students gave synthetic answers in Subtypes 1 and 3 that persisted through different time points. This finding is similar to previous studies that have shown specific answers common to students in different ages (e.g., Gonzales, 1997.) It is possible that information related to these subtypes was not covered in the lesson (e.g. Subtype 1), but also it may be discussed that these answers seemed plausible for students (e.g. Subtype 3) and more specific teaching strategies should be used to support the development of scientific knowledge.

Our results also emphasize that previous knowledge should be explicitly evoked in all classroom lessons. Synthetic answers in Subtype 3 used scientific concepts in relation to the water cycle (e.g. temperature, the atmosphere). Using sophisticated concepts and terminology may give students a false impression that topics have been understood (Eberbach \& Crowley, 2009; Kikas, 2003). In this case, students may not feel the need to restructure their knowledge, and with traditional teaching methods, such synthetic knowledge may become solidified (Sinatra and Mason, 2013). As changes in knowledge are continuous and every new experience can change a student's understanding, it is important to describe long-term knowledge shifts to better understand why answers may move between synthetic subtypes. Diakidoy and Kendeou (2001) suggest that moving between synthetic subtypes may be progressive, thus teachers should pay specific attention to understanding what kind of knowledge students have and how student knowledge changes throughout the lesson.

\section{Limitations}

Some limitations of the present study should be addressed. First, our sample was modest, which limits our ability to make firm conclusions about broader populations. Second, as the goal of the study was to describe changes in knowledge in an ordinary classroom environment, we did not compare teachers' activities. Thus, we cannot infer which teaching methods best support learning. In the future, larger intervention studies should compare and contrast different teaching methods.

Third, in an effort to study the teacher perspective, we relied upon teacher ratings to describe student interest levels. Student engagement (an important part of student interest) has been found to be directly related to the successful development of knowledge (Ainley, Hidi, \& Berndorff, 2002; Kang, Scharmann, Kang, \& Noh, 2010; Krapp, 1999). Although earlier studies have shown high correlations between teacher and student interest ratings (Givvin, Stipek, Salmon \& MacGyvers, 2001; Lee \& Reeve, 2012; Zhu \& Urhahne, 2014), both types of ratings are also influenced by beliefs and knowledge. In our study, a teacher's ability to accurately evaluate student interest levels 
was taken for granted. Incorrect evaluations may have distorted our results. Therefore, future studies may benefit from using student ratings in conjunction with teacher ratings.

Fourth, we used open-ended questions to describe student knowledge. Some researchers argue that open-ended questions distract students and evoke misconceptions (Diakidoy, Kendeou, 2001; Vosniadou \& Brewer, 1994). Also it is a possibility that our coding system may have been too rough and listed students' answers to lower categories when compared to prior studies. However, with multiple-choice questions, it is possible that a student may recognize the correct answer without having a true scientific understanding of the concept. Therefore, considering everyday and synthetic concepts specifically, it is important to let students freely describe their understanding.

\section{Implications}

Our study described student knowledge about the water cycle in terms of everyday, synthetic, and scientific answers. Our findings can help teachers better understand 1) how student knowledge changes with the presentation of new scientific information, and 2) the role interest plays in student understanding. Our findings may also help teachers 1) offer students new possibilities to use their knowledge in a variety of contexts, and 2) encourage students to understand when topics have not yet been mastered. Teachers may also benefit from the realization that higher student interest may support the formation of both scientific and synthetic knowledge. Moreover, teacher perceptions of student interest and other motivational factors are important to study as these perceptions may impact our understanding about how to best support student knowledge development.

Our findings indicate that interest alone may be an insufficient indicator of when, why, and how student knowledge changes. Therefore, future studies should consider other motivational and cognitive variables. Follow-up studies should also analyze the effects of different conceptual-change oriented teaching methods on student knowledge development.

\section{Acknowledgements}

This study was supported by the Estonian Ministry of Education and Research (grant IUT03-03). Authors would like to thank all the schools that participated in the study and Dashiell Oatman-Stanford for the extensive help with language editing.

\section{References}

Ainley, M., Hidi, S., \& Berndorff, D. (2002). Interest, learning, and the psychological processes that mediate their relationship. Journal of Educational Psychology, 94(3), 545-561. https://doi.org/10.1037/0022-0663.94.3.545

Andre, T., \& Windschitl, M. (2003). Interest, epistemological belief, and intentional conceptual change. In G. M. Sinatra \& P. R. Pintrich (Eds.), Intentional Conceptual Change (pp. 173-197). Mahwah, NJ: Lawrence Erlbaum.

Ben-zvi-Assarf, O., \& Orion, N. (2005). A study of junior high students' perceptions of the water cycle. Journal of Geoscience Education, 53(4), 366-373. https://doi.org/10.5408/1089-9995-53.4.366

Bruner, J. (1960/1999). The process of education. Cambridge, MA: Harvard UP.

Cardak, O. (2009). Science students' misconceptions of the water cycle according to their drawings. Journal of Applied Sciences, 9(5), 865-873. https://doi.org/10.3923/jas.2009.865.873

Carey, S., \& Smith, C. (1993). On understanding the nature of scientific knowledge. Educational Psychologist, 28(3), 235-251. https://doi.org/10.1207/s15326985ep2803_4

Covitt, B. A., Gunckel, K. L., \& Anderson, C. W. (2009). Students' developing understanding of water in environmental systems. The Journal of Environmental Education, 40(3), 37-51. https://doi.org/10.3200/JOEE.40.3.37-51

Diakidoy, I. A. N., \& Kendeou, P. (2001). Facilitating conceptual change in astronomy: A comparison of the effectiveness of two instructional approaches. Learning and Instruction, 11(1), 1-20. https://doi.org/10.1016/S0959-4752(00)00011-6

Diakidoy, I. A., Vosniadou, S., \& Hawks, J. D. (1997). Conceptual change in astronomy: Models of the earth and of the day/night cycle in American-Indian children. European Journal of Psychology of Education, 12(2), 159-184. https://doi.org/10.1007/BF03173083

Disessa, A. A. (2002). Why "conceptual ecology" is a good idea. In M. Limon \& L. Mason (Eds.), Reconsidering Conceptual Change. Issues in Theory and Practice, 29-60 (pp. 28-60). Dordrecht: Springer 
Duit, R. H., \& Treagust, D. F. (2012). Conceptual change: Still a powerful framework for improving the practice of science instruction. In K. C. D. Tan, \& M. Kim (Eds.), Issues and Challenges in Science Education Research (pp. 43-54). Netherlands: Springer.

Eberbach, C., \& Crowley, K. (2009). From everyday to scientific observation: How children learn to observe the $\begin{array}{lllll}\text { biologist's world. Review of Educational Research, } & \text { 79(1), }\end{array}$ https://doi.org/10.3102/0034654308325899

Eccles, J. S. (2005). Subjective task value and the Eccles et al. model of achievement-related choices. In A. J. Elliot \& C. S. Dweck (Eds.), Handbook of Competence and Motivation (pp.105-121). New York: The Guilford Press.

Eccles, J. S., \& Wigfield, A. (1995). In the mind of the actor: The structure of adolescents' achievement task values and expectancy-related beliefs. Personality and Social Psychology Bulletin, 21(3), 215-225. https://doi.org/10.1177/0146167295213003

Frappart, S., \& Frède, V. (2016). Conceptual change about outer space: how does informal training combined with formal teaching affect seventh graders' understanding of gravitation?. European Journal of Psychology of Education, 31(4), 515-535.

Givvin, K. B., Stipek, D. J., Salmon, J. M., \& MacGyvers, V. L. (2001). In the eyes of the beholder: Students' and teachers' judgments of students' motivation. Teaching and Teacher Education, 17(3), 321-331. https://doi.org/10.1016/S0742-051X(00)00060-3

González, F. M. (1997). Diagnosis of Spanish primary school students' common alternative science conceptions. School Science and Mathematics, 97(2), 68-74. https://doi.org/10.1111/j.1949-8594.1997.tb17345.x

Hadjiachilleos, S., Valanides, N., \& Angeli, C. (2013). The impact of cognitive and affective aspects of cognitive conflict on learners' conceptual change about floating and sinking. Research in Science \& Technological Education, 31(2), 133-152. https://doi.org/10.1080/02635143.2013.811074

Hannust, T., \& Kikas, E. (2007). Children's knowledge of astronomy and its change in the course of learning. Early Childhood Research Quarterly, 22(1), 89-104.

Henriques, L. (2002). Children's ideas about weather: A review of the literature. School Science and Mathematics, 102(5), 202-215. https://doi.org/10.1111/j.1949-8594.2002.tb18143.x

Kang, H., Scharmann, L. C., Kang, S., \& Noh, T. (2010). Cognitive conflict and situational interest as factors influencing conceptual change. International Journal of Environmental and Science Education, 5(4), 383-405.

Kikas, E. (1998a). The impact of teaching on students' definitions and explanations of astronomical phenomena. Learning and Instruction, 8(5), 439-454.

Kikas, E. (1998b). Pupils' explanations of seasonal changes: Age differences and the influence of teaching. British Journal of Educational Psychology, 68(4), 505-516.

Kikas, E. (2003). Constructing Knowledge Beyond the Senses: Worlds Too Big and Too Small to See. In A. Toomela (Ed.), Cultural guidance in the development of the human mind (pp. 211-227). Westport: Ablex Publishing.

Krapp, A. (1999). Interest, motivation and learning: An educational-psychological perspective. European Journal of Psychology of Education, 14(1), 23-40. https://doi.org/10.1007/BF03173109

Larraín, A. (2017). Argumentation and concept development: the role of imagination. European Journal of Psychology of Education, 32(4), 521-536.

Lee, W., \& Reeve, J. (2012). Teachers' estimates of their students' motivation and engagement: Being in synch with students. Educational Psychology, 32(6), 727-747. https://doi.org/10.1080/01443410.2012.732385

Linnenbrink, E. A., \& Pintrich, P. R. (2002). Motivation as an enabler for academic success. School Psychology Review, 31(3), 313-327.

Linnenbrink-Garcia, L., Pugh, K. J., Koskey, K. L., \& Stewart, V. C. (2012). Developing conceptual understanding of natural selection: The role of interest, efficacy, and basic prior knowledge. The Journal of Experimental Education, 80(1), 45-68. https://doi.org/10.1080/00220973.2011.559491

Malleus, E., Kikas, E., \& Marken, T. (2017). Kindergarten and primary school children's everyday, synthetic, and scientific concepts of clouds and rainfall. Research in Science Education, 47(3), 539-558. 
Özdemir, G., \& Clark, D. B. (2007). An Overview of Conceptual Change Theories. Eurasia Journal of Mathematics, Science \& Technology Education, 3(4).

Panagiotaki, G., Nobes, G., \& Banerjee, R. (2006). Is the world round or flat? Children's understanding of the earth. European Journal of Developmental Psychology, 3(2), 124-141.

Pintrich, P. R., Marx, R. W., \& Boyle, R. A. (1993). Beyond cold conceptual change: The role of motivational beliefs and classroom contextual factors in the process of conceptual change. Review of Educational Research, 63(2), 167-199.

Schiefele, U. (1999). Interest and learning from text. Scientific Studies of Reading, 3(3), 257-279. https://doi.org/10.1207/s1532799xssr0303_4

Sibley, D. F., Anderson, C. W., Heidemann, M., Merrill, J. E., Parker, J. M., \& Szymanski, D. W. (2007). Box diagrams to assess students' systems thinking about the rock, water and carbon cycles. Journal of Geoscience Education, 55(2), 138-146. https://doi.org/10.5408/1089-9995-55.2.138

Sinatra, G. M. (2005). The" warming trend" in conceptual change research: The legacy of Paul R. Pintrich. Educational Psychologist, 40(2), 107-115. https://doi.org/10.1207/s15326985ep4002_5

Sinatra, G. M., \& Mason, L. (2013). Beyond knowledge: Learner characteristics influencing conceptual change. In S. Vosniadou (Ed.), International Handbook of Research on Conceptual Change (pp. 377-394). New York: Routledge.

Sinatra, G. M., Brem, S. K., \& Evans, E. M. (2008). Changing minds? Implications of conceptual change for teaching and learning about biological evolution. Evolution: Education and Outreach, 1(2), 189-195. https://doi.org/10.1007/s12052-008-0037-8

Soderstrom, N. C., \& Bjork, R. A. (2015). Learning versus performance: An integrative review. Perspectives on Psychological Science, 10(2), 176-199.

Taiwo, A. A., Ray, H., Motswiri, M. J., \& Masene, R. (1999). Perceptions of the water cycle among primary school children in Botswana. International Journal of Science Education, 21(4), 413-429. https://doi.org/10.1080/095006999290633

Teaching and Learning International Survey. (2009). Organization for Economic Co-operation and Development. Retrieved from http://www.oecd.org/edu/talis/firstresults

Teaching and Learning International Survey. (2013). Organization for Economic Co-operation and Development. Retrieved

from

http://www.keepeek.com/Digital-Asset-Management/oecd/education/talis-2013-results_9789264196261-en \#.WVOduGjyjb0

Thompson, F., \& Logue, S. (2006). An exploration of common student misconceptions in science. International Education Journal, 7(4), 553-559.

Toomela, A. (2003). Development of symbol meaning and the emergence of the semiotically mediated mind. In A. Toomela (Ed.), Cultural guidance in the development of the human mind (pp. 163-209). Westport: Ablex Publishing.

Tytler, R. (2000). A comparison of Year 1 and Year 6 students' conceptions of evaporation and condensation: Dimensions of conceptual progression. International Journal of Science Education, 22(5), 447-467. https://doi.org/10.1080/095006900289723

Tytler, R. (2002). Teaching for understanding in science: Student conceptions research, \& changing views of learning. Australian Science Teachers Journal, 48(3), 14-21.

Vabariigi Valitsus (2011/ 2018). Põhikooli ja gümnaasiumi riiklik õppekava. [National Curriculum for Basic Schools and Upper Secondary Schools], Riigi Teataja I 2011, 1, 14. Retrieved from https://www.riigiteataja.ee/akt/129082014021

Varelas, M., Pappas, C. C., \& Rife, A. (2006). Exploring the role of intertextuality in concept construction: Urban second graders make sense of evaporation, boiling, and condensation. Journal of Research in Science Teaching, 43(7), 637-666. https://doi.org/10.1002/tea.20100

Venville, G. J., \& Treagust, D. F. (1998). Exploring conceptual change in genetics using a multidimensional interpretive framework. Journal of Research in Science Teaching, 35(9), 1031-1055. 
Vosniadou, S. (1994). Capturing and modeling the process of conceptual change. Learning and Instruction, 4(1), 45-69. https://doi.org/10.1016/0959-4752(94)90018-3

Vosniadou, S. (2012). Reframing the classical approach to conceptual change: Preconceptions, misconceptions and synthetic models. In B.J. Fraser, K. Tobin, \& C. J. McRobbie (Eds.), Second International Handbook of Science Education (pp. 119-130). Netherlands: Springer.

Vosniadou, S., \& Brewer, W. F. (1992). Mental models of the earth: A study of conceptual change in childhood. Cognitive Psychology, 24(4), 535-585. https://doi.org/10.1016/0010-0285(92)90018-W

Vosniadou, S., \& Skopeliti, I. (2014). Conceptual change from the framework theory side of the fence. Science \& Education, 23(7), 1427-1445.

Vosniadou, S., \& Skopeliti, I. (2017). Is it the Earth that turns or the Sun that goes behind the mountains? Students' misconceptions about the day/night cycle after reading a science text. International Journal of Science Education, 39(15), 2027-2051.

Vosniadou, S., Ioannides, C., Dimitrakopoulou, A., \& Papademetriou, E. (2001). Designing learning environments to promote conceptual change in science. Learning and Instruction, 11(4), 381-419. https://doi.org/10.1016/S0959-4752(00)00038-4

Vosniadou, S., Skopeliti, I., \& Ikospentaki, K. (2004). Modes of knowing and ways of reasoning in elementary astronomy. Cognitive Development, 19(2), 203-222. https://doi.org/10.1016/j.cogdev.2003.12.002

Vygotsky, L. S. (1986). Thought and language. Cambridge: MIT Press.

Wigfield, A. (1994). Expectancy-value theory of achievement motivation: A developmental perspective. Educational Psychology Review, 6(1), 49-78. https://doi.org/10.1007/BF02209024

Wigfield, A., \& Cambria, J. (2010). Students' achievement values, goal orientations, and interest: Definitions, development, and relations to achievement outcomes. Developmental Review, 30(1), 1-35. https://doi.org/10.1016/j.dr.2009.12.001

Wigfield, A., \& Eccles, J. S. (1992). The development of achievement task values: A theoretical analysis. Developmental review, 12(3), 265-310. https://doi.org/10.1016/0273-2297(92)90011-P

Wigfield, A., \& Eccles, J. S. (2000). Expectancy-value theory of achievement motivation. Contemporary Educational Psychology, 25(1), 68-81. https://doi.org/10.1006/ceps.1999.1015

Wiser, M., \& Amin, T. (2001). "Is heat hot?” Inducing conceptual change by integrating everyday and scientific perspectives on thermal phenomena. Learning and Instruction, 11(4), 331-355. https://doi.org/10.1016/S0959-4752(00)00036-0

Zhu, M., \& Urhahne, D. (2014). Assessing teachers' judgements of students' academic motivation and emotions across two rating methods. Educational Research and Evaluation, 20(5), 411-427. https://doi.org/10.1080/13803611.2014.964261 
Appendix A. An example of Configural Frequency analysis output for T1 according to groups of interest and answer type

\begin{tabular}{|c|c|c|c|c|}
\hline $\begin{array}{c}\text { Pairs of } \\
\text { interest group } \\
\mathrm{X} \text { answer } \\
\text { type* }\end{array}$ & $\begin{array}{l}\text { Observed } \\
\text { frequency }\end{array}$ & Expected frequency & $\chi^{2}$ & $\mathrm{p}$ \\
\hline 10 & 10 & .58 & .58 & .26 \\
\hline 20 & 15 & 13.66 & .13 & .39 \\
\hline 30 & 7 & 10.48 & 1.16 & .17 \\
\hline 11 & 12 & 9.58 & .61 & .25 \\
\hline 21 & 20 & 16.65 & .67 & .23 \\
\hline 31 & 7 & 12.77 & 2.61 & .06 \\
\hline 12 & 8 & 6.63 & .28 & .36 \\
\hline 22 & 13 & 11.53 & .19 & .37 \\
\hline 32 & 6 & 8.84 & .91 & .21 \\
\hline 13 & 5 & 6.88 & .51 & .31 \\
\hline 23 & 12 & 11.95 & .00 & .54 \\
\hline 33 & 11 & 9.17 & .37 & .32 \\
\hline 14 & 5 & 4.67 & .02 & .51 \\
\hline 24 & 5 & 8.11 & 1.19 & .17 \\
\hline 34 & 9 & 6.22 & 1.24 & .17 \\
\hline 15 & 2 & 5.65 & 2.36 & .08 \\
\hline 25 & 7 & 9.82 & .81 & .23 \\
\hline 35 & 14 & 7.53 & 5.55 & .02 \\
\hline 16 & 0 & .74 & .74 & .47 \\
\hline 26 & 1 & 1.28 & .06 & .63 \\
\hline 36 & 2 & .98 & 1.05 & .26 \\
\hline
\end{tabular}

* First number refers to Interest group (1-Low; 2-Average; 3-High) and second number refers to answer type (0-Don't know, 1-everyday, 2-synthetic category 1, 3-synthtic category 2, 4-synthetic category 3, 5-synthetic category 4, 6-scientific.

\section{Copyrights}

Copyright for this article is retained by the author(s), with first publication rights granted to the journal.

This is an open-access article distributed under the terms and conditions of the Creative Commons Attribution license (http://creativecommons.org/licenses/by/4.0/). 